\section{Late-onset anorexia nervosa}

SIR: I read the paper on late-onset anorexia nervosa by Boast et al (Journal, February 1992, 160, 257-260) with great interest. This well-established service gives the opportunity to review cases over a 16-year period, generating numbers suitable for statistical analysis. Six women with late-onset anorexia nervosa (over 25) presented to the Leicestershire Eating Disorders Service between 1983 and 1991 (age of onset: mean 31 years, s.d. 3.5). Of patients over 16 presenting with this diagnosis, $6 \%$ were late-onset cases. This is consistent with the findings of Garfinkel \& Garner (1982).

The paper identifies older patients as losing more weight than the younger group. The authors suggest this may be a possible referral bias. For our service, taking patients mainly from Leicestershire, the mean body mass index at presentation was higher for the late-onset group $\left(17.5 \mathrm{~kg} / \mathrm{m}^{2}\right.$ compared with $14.8 \mathrm{~kg} / \mathrm{m}^{2}$ for case-matched controls under 20 ).

It is pertinent to ask why women become eating disordered only later in life. Anorexia nervosa developing in the context of a depressive illness appears a sound proposition. Three of our six late-onset cases had a history of depression before the onset of anorexia nervosa. An additional two became markedly depressed during out-patient treatment. They had the associated symptoms of depressive illness which responded to antidepressant medication. Two of the Leicestershire late-onset cases developed anorexia nervosa soon after childbirth. Literature on the association between pregnancy, motherhood and eating disorders has been prominent recently (Fahy \& O'Donoghue, 1991).

Conceptualising anorexia nervosa as a disorder of adolescence may deter older women from coming forward. Eating disorders in older women deserve a higher profile; perhaps then a more accurate indication of the true prevalence could develop.

FAнY, T. A. \& O'Donoghue, G. (1991) Eating disorders and pregnancy. Psychological Medicine, 21, 577-580.

Garfinkel, P. E. \& Garner, D. M. (1982) Anorexia Nervosa: A Multidimensional Approach. New York: Brunner and Mazel.

Leicester General Hospital

C. BOWLER

Gwendolen Road

Leicester LE5 4PW

\section{Sexual abuse and referral bias}

SIR: Waller (Journal, November 1991, 159, 664-671) clearly demonstrated an excess of bulimic patients with a history of sexual abuse compared with their anorexic counterparts. There is an explanation which was not explored in the study. There may be a bias on the part of the patient or the referrer to seek specialist treatment for bulimia when a history of sexual abuse is an additional factor. A higher relative rate of disclosure of sexual abuse to the referring agent among the bulimic patients might point to such a process.

I investigated a similar phenomenon as part of a case-note study of 190 women referred to the Nottingham Puerperal Mental Illness Unit between July 1989 and July 1990. Previous work had shown that women presenting in the year following childbirth are more severely ill than men and women in the same age group and are more likely to be suffering from manic-depression (Oates, 1988). I found that minor depressive episodes and adjustment disorders, although not normally referred to psychiatric services, accounted for the large majority of diagnoses associated with the childhood sexual abuse (CSA). The overall rate of reported CSA was $8 \%$. Of the 16 women referred in pregnancy $44 \%$ reported CSA, as compared with $4.7 \%$ of post-natal women (8 of 174 ). Of those reporting a history of CSA, a higher proportion of those referred in pregnancy disclosed to the referrer as compared to the post-natal group. The difference was not significant because of the small numbers involved. However, since only a small proportion of mild disorder in pregnancy is referred to the Puerperal Mental Illness Unit, the data suggests that disclosure of CSA lowers the threshold for specialist referral in pregnancy.

This raises the possibility that a similar process might operate in eating-disordered patients. Fairburn \& Cooper (1984) have shown that only a minority of women with bulimic symptoms seek specialist treatment, so that if the referral threshold was lowered by the disclosure of sexual abuse, this would account for Dr Waller's findings.

Fairburn, C. G. \& CoOPER, P. J. (1984) Binge-eating, self-induced vomiting and laxative abuse; a community study. Psychological Medicine, 144, 401-410.

O^tes, M. (1988) In Motherhood and Mental Illness. vol. II, (eds R. Kumar \& I. S. Brockington), pp. 133-158. Guildford: J. Wright.

Department of Psychiatry

Peter Bell

Queen's Medical Centre

Nottingham NG7 2UH

\section{Screening for depression in the medically ill}

SIR: Meakin (Journal, February 1992, 160, 212-216) advocates response to treatment with tricyclic antidepressants for validating paper and pencil tests 
for depression in the medically ill. He claims that satisfactory screening for the symptoms of major depression demonstrates the usefulness of pencil and paper tests to non-psychiatrists. However, the validity of the concept of major depression and the indications for tricyclic drugs in the medically ill with depression have not been satisfactorily established.

Psychological symptoms are distributed continuously in the medical population with no clear separation between the psychiatrically ill and normal subjects. Proportionally more physically ill subjects have high numbers of psychological symptoms because the distribution curve is shifted to the right compared with the community population (House, 1988). A high number of medically ill patients will therefore be diagnosed as suffering from major depression. Since the latter concept was derived from observations of psychiatric patients, it cannot be assumed that a diagnosis of major depression implies the same need for antidepressant treatment in the medically ill. Most cases of significant depression occur because of the patient's awareness of the illness and its implications. Many of these episodes tend to be short-lived, resolve spontaneously (Lloyd \& Cawley, 1983) or require psychosocial forms of treatment. Antidepressants are indicated in the medically ill when major depression precedes a significant medical illness, depressive symptoms are severe, or when they do not resolve after a few months. The role of antidepressants in the treatment of depression in the medically ill is otherwise unclear (Lloyd, 1991) and requires further research.

The specificity and sensitivity of pencil and paper tests for psychiatric disorders for medically ill patients should first be evaluated in terms of prognosis. Tests which identify patients with depression that does not resolve spontaneously after a few months would be extremely useful. Until then, paper and pencil tests for psychiatric disorders have a limited role in clinical practice for non-psychiatrists. There is now good evidence that the detection and management of psychiatric disorders by nonpsychiatrists can be improved by a short course of interviewing training (Gask et al, 1987). This may be a better alternative for improving psychiatric detection and management in the general hospital.

Gask, L., McGrath, G., Goldberg, D. P., et al (1987) Improving the psychiatric skills of established general practitioners: evaluation of group training. Medical Education, 21, 362-368.

HousE, A. (1988) Mood disorders in the physically ill: problems of definition and measurement. Journal of Psychosomatic Research, 32, 345-353.

LloYd, G. G. (1991) Texibook of General Hospital Psychiatry. Edinburgh: Churchill Livingstone.
LLOYD, G. G. \& CAWLEY, R. H. (1983) Distress or illness? A study of psychological symptoms after myocardial infarction. British Journal of Psychiatry, 142, 120-125.

Department of Psychiatry

RICHARD K. MORRISS

University Hospital of South Manchester

West Didsbury

Manchester M20 8LR

\section{Systemic family therapy in adult psychiatry}

SIR: I read with interest the paper by Bloch et al (Journal, September 1991, 159, 357-364). We would agree that there is a need for increased systemic understanding in adult psychiatric practice.

We have had a Brief Therapy clinic in this hospital for three years. Unlike the Milan style favoured by Professor Bloch, we use work derived from the Mental Research Institute and the writings of Steve de Shazer (Fisch et al, 1982; de Shazer, 1988). We have found their approach to be of value in numerous cases. The clinic provides training in systemic work for hospital staff of various disciplines. An outcome study is in progress and early results are promising.

Fisch, R., Weakland, J. H. \& Segal, L. (1982) The Tactics of Change: Doing Therapy Briefly. San Francisco: Jossey-Bass. DE SHAZER, S. (1988) Clues: Investigating Solutions in Brief Therapy. New York: Norton.

Alasdair J. MaCDONAld

Crichton Royal Hospital

Dumfries DGI 4TG

Scotland

\section{Service use by Indian immigrants}

SIR: I read with great interest Sunjai Gupta's paper (Journal, August 1991, 159, 222-225), which is thought-provoking. He does admit the need for further study about the genuine differences in the outcome determinants of psychosis in first-generation Asian immigrants.

I believe that any prospective study in future in relation to service utilisation and determinants of outcome in psychiatric disorders among Asians should take into consideration the "pathway to psychiatric care for Asian patients'. My clinical impression, having worked with a large population of Asians in Leicester, is that almost $30-50 \%$ of my patients, both before and after contact with the psychiatric services, visit traditional healers, hakims, etc. These alternative pathways are pursued either in the UK or abroad. Psychiatric practice in India suggests onethird of patients had treatment with faith healers before the first consultation (Trivedi \& Settu, 1980). 